UCRL-53321

Distribution Category UC-11

UCRL -53321

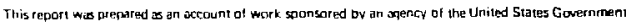

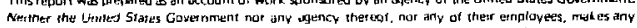

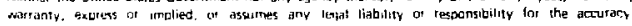

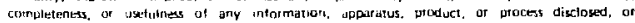

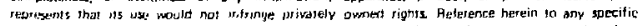

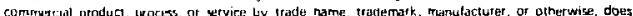

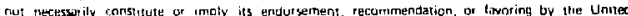

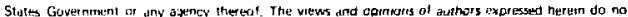

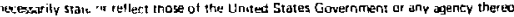

\title{
A Time-Domain Study of Tectonic Strain-Release Effects on Seismic Waves from Underground Nuclear Explosions
}

\author{
K. K. Nakanishi \\ N. W. Sherman
}

Manuscript date: September 1982 
Abstract

Introduction

Analysis in the Time Domain .

The Effect of Tectonic Strain Release on Magnitudes

The Effect of Tectonic Strain Release on Rayleigh Wave Delays . . . 12

Implications for Tectonics of the Source Region . . . . . . . . 22

Summary • • • • • • • • • • • • • • • • • • • • • • 23

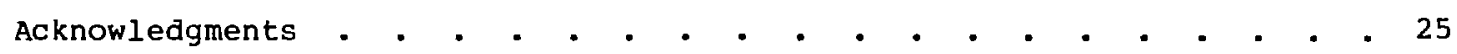

References . . . . . . . . . . . . . . . . . . . . . . 26 
A TIME DOMAIN STUDY OF TECTONIC STRAIN RELEASE EFFECTS

ON SEISMIC WAVES FROM UNDERGROUND NUCLEAR EXPLOSIONS

ABSTRACT

Tectonic strain release affects both the amplitude and phase of seismic waves from underground nuclear explosions. Surface wave magnitudes are strongly affected by the component of tectonic strain release in the explosion. Amplitudes and radiation patterns of surface waves from explosions with even small tectonic components change magnitudes significantly and show a strong dependence on receiver locations. A thrust-slip source superimposed on an isotropic explosion can explain observed reversals in waveform at different azimuths and phase deiays between normal and reversed Rayleigh waves. The mechanism of this reversal is due to the phase relationship between reasonable explosion and tectonic release sources. Spallation or an unusual source time function are not required. The observations of Shagan River events imply thrust-slip motion along faults in a northwest-southeast direction, which is consistent with regional tectonics.

\section{INTRODUCTION}

Seismology is one of the primary tools used in the detection and identification of underground nuclear explosions. In addition, the yield of the device can be estimated by measuring the amplitude of the seismic signals. It is, therefore, of primary importance in determining the relationship between yield and seismic amplitude. Seismic signals are frequently complicated by interference from secondary sources and noise, making them difficult to analyze and interpret.

Observations of seismic data indicate that underground nuclear explosions cannot be modeled by an isotropic source alone (Brune and Pomeroy, 1963; Aki, 1964; Aki and Tsai, 1972; Toksöz and Kehrer, 1972). Features such as Love waves cannot be explained by the isotropic (explosion) part of the seismic source in a flat, layered medium. These features are generally attributed to 
the deviatoric (earthquake) part of the source, consisting of either stress relaxation (Archambeau, 1964), or motion on a nearby fault (Brune and Pomeroy, 1963).

We are primarily interested in the effect of tectonic strain release on signals from the Shagan River region of the Soviet Union test area in eastern Kazakhstan. A map of the region is found in Rodean (1979). Anomalies exist in the surface waves of some Soviet explosions in this regicin. Rygg (1979), Cleary (1981), and North and Fitch (1982) all report events displaying phase reversals in Rayleigh waves when compared to "normal" explosions. Other anomalies sometimes observed are enhanced amplitudes in certain quadrants, enhanced Love wave signals at certain azimuths, and delays in the reversed Rayleigh waves when compared to normal explosions.

Any great variation in explosion surface waves, particularly enhancement, would complicate earthquake-explosion discrimination, especially if the wellaccepted $M_{s}-m_{b}$ criterion were being used (Evernden et al., 1971). In addition, using $M_{S}$ to determine device yield would give inaccurate results.

In this study we use synthetic seismograms of $P-$ and Rayleigh waves to address:

1. The effect of tectonic strain release on magnitudes as determined by two different station distributions (one distribution axially symmetric and the other with a more realistis distribution).

2. The effect of tectonic strain release on the reversals and phase delays of Rayleigh waveforms.

3. The relationship of models in this study and with the geology and geophysics of the region.

ANALYSIS IN THE TIME DOMAIN

Previous studies of the effect of tectonic strain release by Patton (1980) and Harkrider (1981) were performed in the frequency domain. Our study considers computations in the time domain in order to duplicate the procedure for measuring magnitude and to construct data from which reversals and delays can be measured. The primary difference bətween studies in the time domain and those in the frequency domain is that the effect of wave propagation is included in the synthetic seismogram in time domain work. 
The synthetic seismograms are computed using the method of Douglas et al. (1972). Measurements are restricted to distances between $25^{\circ}$ and $95^{\circ}$. The source is assumed to be located at $50.011^{\circ} \mathrm{N}, 78.95^{\circ} \mathrm{E}--a n$ arbitrarily chosen location in the Shagan River test region. The receivers are distributed in two configurations. The first consists of stations $45^{\circ}$ away at equal azimuthal spacing of $15^{\circ}$ intervals. This configuration will be called the "axisymmetric" case. The other configuration is realistic, with receiver locations corresponding to the Seismic Research observatory (SRO) stations (Table 1). This configuration is representative of the distribution of seismograph stations used to monitor explosions in the Soviet Union.

Amplitude measurements and waveform comparisons are done on seismograms computed by convolution of the synthetic displacementgrams with the appropriate seismometer. For P-waves, the seismometer corresponds to the

Table 1. Location of seismic stations in the realistic configuration with respect to $50.011 \mathrm{~N}, 78.950 \mathrm{E}$. The strike is assumed to be $140^{\circ}$ clockwise from north.

\begin{tabular}{lr}
$\begin{array}{c}\text { Distance } \\
\text { (deg) }\end{array}$ & $\begin{array}{r}\text { Azimuth from strike } \\
\text { (deg) }\end{array}$ \\
\hline 26.38 & 12.94 \\
33.72 & 130.48 \\
35.03 & 5.58 \\
39.31 & 171.40 \\
41.21 & 331.36 \\
42.29 & 156.73 \\
44.07 & 304.39 \\
64.25 & 319.75 \\
67.93 & 109.29 \\
89.28 & 8.59 \\
91.54 & 339.84 \\
95.28 & 224.46 \\
\hline
\end{tabular}


transfer function of a WWSSN short-period instrument, with unity pass at 1 s. For Rayleigh waves, the seismometer is the response of a WWSSN long-period instrument, with unity pass at $20 \mathrm{~s}$. The resultant seismograms are peaked at $1 \mathrm{~s}$ for P-waves and $20 \mathrm{~s}$ for the Rayleigh waves. These periods are convenient for measuring the amplitudes in the time domain used in computing magnitudes.

The seismic source consists of an isotropic (explosion) part and a deviatoric (earthquake) part. The isotropic part is assumed to be a 150-kt explosion in granite. Haskell (1967), Mueller and Murphy (1971), and Von Seggern and Blandford (1972) published different analytic models of the explosion source time function. The primary difference between the models lies in the high-frequency rolloff of the amplitude; these differences are not significant concerning the excitation of l-s P-waves or 20-s Rayleigh waves. We chose to use the Haskell source time function. When exciting Rayleigh waves, it is important to note that the Haskell model is close to, but not exactly the same as a step source time function. This difference between the Haskell and step source time function must be kept in mind to understand the following analysis. (This difference is illustrated in Figs. 1 and 2.) Patton (1980) used step source time functions for both the isotropic and deviatoric sources.

The deviatoric part of the source is represented by a double-couple coincident with the isotropic part in space. A circular fault of radius $1.7 \mathrm{~km}$ is chosen using the fault model of Savage (1966). The source size is selected so that the 1-s measurement occurs on the flat, low-frequency end of the spectrum rather than on the high-frequency rolloff end. Two types of fault mechanisms are considered: strike-slip motion on a vertical fault plane and thrust-slip motion with $45^{\circ} \mathrm{dip}$. The source spectrum for the Savage model is illustrated in Figs. 1 and 3. As seen in Fig. 1, the amplitude spectra for the isotropic sources are much richer in high frequencies than are the spectra for the deviatoric source. The phase spectrum (Fig. 3) for the Savage source differs from that of a step function.

The proportion of isotropic to deviatoric source is indicated by the "F" factor, defined by Müller (1973) as

$F=\frac{v_{p}^{2}}{2 v_{s}^{2}} \frac{M_{D}}{M_{I}}$, 


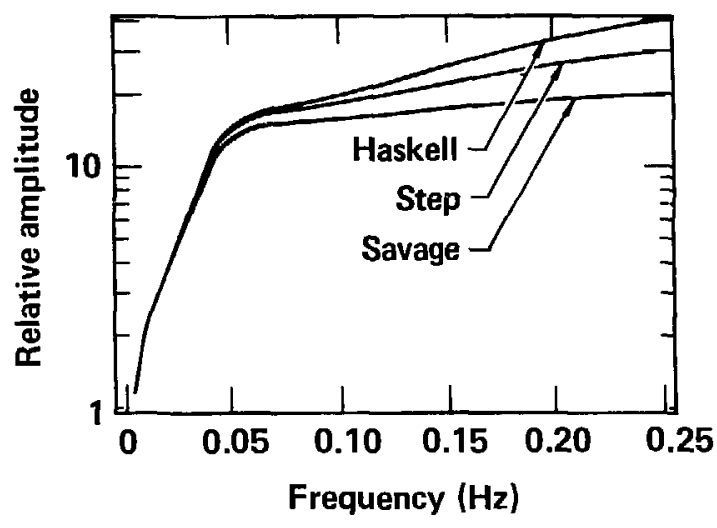

Figure 1. Amplitude spectra for an isotropic source with both a step and Haskell source time function, and a deviatoric source using Savage's model. The spectra are ncrmalized to the same long-term level.
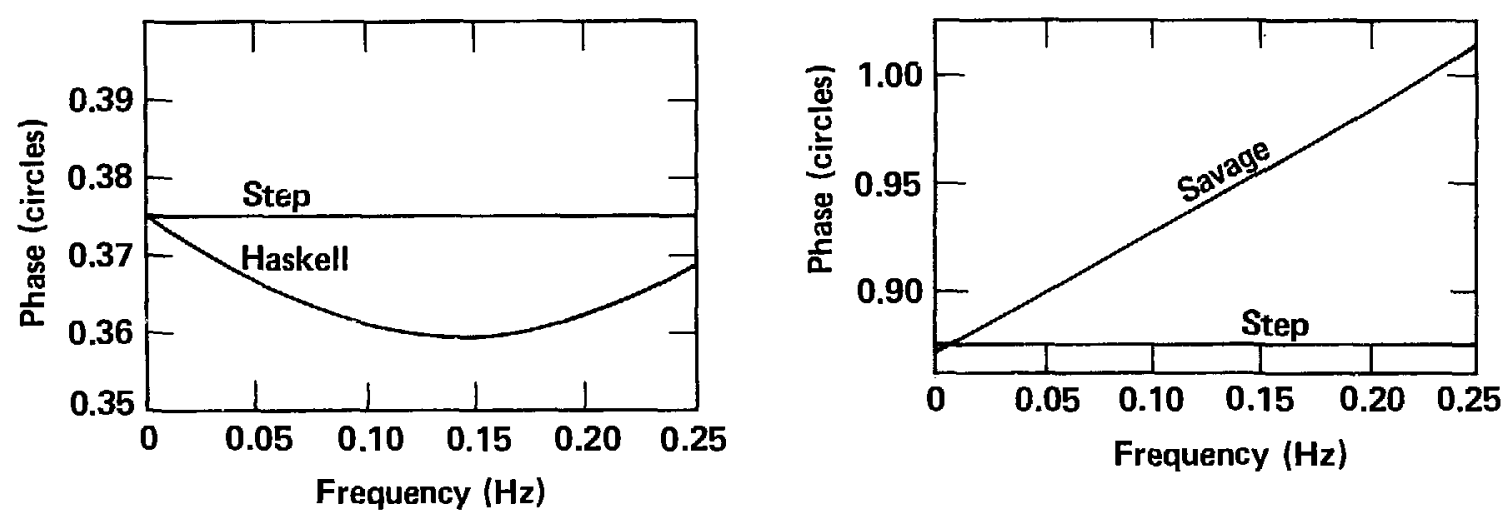

Figure 2. Scurce phase spectra for an isotropic source with both a step and Haskell source time function.

Figure 3. Source phase spectra for a deviatoric source with both a step and Savage model.

where $V_{p}$ and $V_{s}$ are the compressional and shear wave velocities, and $M_{D}$ and $M_{I}$ are the scalar moments of the deviatoric and isotropic parts. The scalar seismic moment of the isotropic part is

$M_{I}=4 \pi \rho V_{\mathrm{p}}^{2} \psi(\infty)$

where $\rho$ is the density and $\psi(\infty)$ is the static level of the reduced dispiacement potential (Miiller, 1973). This static level is both media- and yield-dependent (Haskell, 1967). For $150 \mathrm{kt}$ in granite,

$M_{I}=5.9 \times 10^{23}$ dyne-cm.

The moment for the deviatoric part is obtained from Brune $(1970)$, 
$M_{D}=\frac{16}{7} \sigma r^{3}$

$=9.46 \times 10^{21} \sigma$ dyne-cm

where $\sigma$ is the stress drop in bars. In Fig. 4, we illustrate the stress drop needed for a particular $F$ value, using the $M_{I}$ for $150 \mathrm{kt}$. The $F$ values for NTS events are usually less than 3 (Toksöz and Kehrer, 1972; Patton and vergino, 1981). Reviewing Fig. 4, this corresponds to a stress drop of about 125 bars--a reasonable value for small earthquakes.

The earth structures through which the $\mathrm{P}$-waves propagate are indicated in Tables 2 and 3 . The source region model is a modified version (thicker crust) of the Kazakhstan model of Douglas et al. (1974). The receiver model is similar to the crustal structure beneath Yellowknife, Canada (Douglas, 1980). The ray path between the source and receiver crustal structures is approximated by a Jeffreys-Eullen mantle in which only the effects of geometric spreading and attenuation are considered. The reflectivity response is included for propagation through the crustal structures. We assume a value of 1 for $t^{*}$ (travel time divided by $Q$ ) for the P-wave path. For the Rayleigh waves, we use a plane-layered crustal structure over a half-space mantle (Table 4). The attenuation is computed explicitly for the parameters in Table 4.

Figure 4. Stress drop needed in the deviatoric component at a given $F$ value.

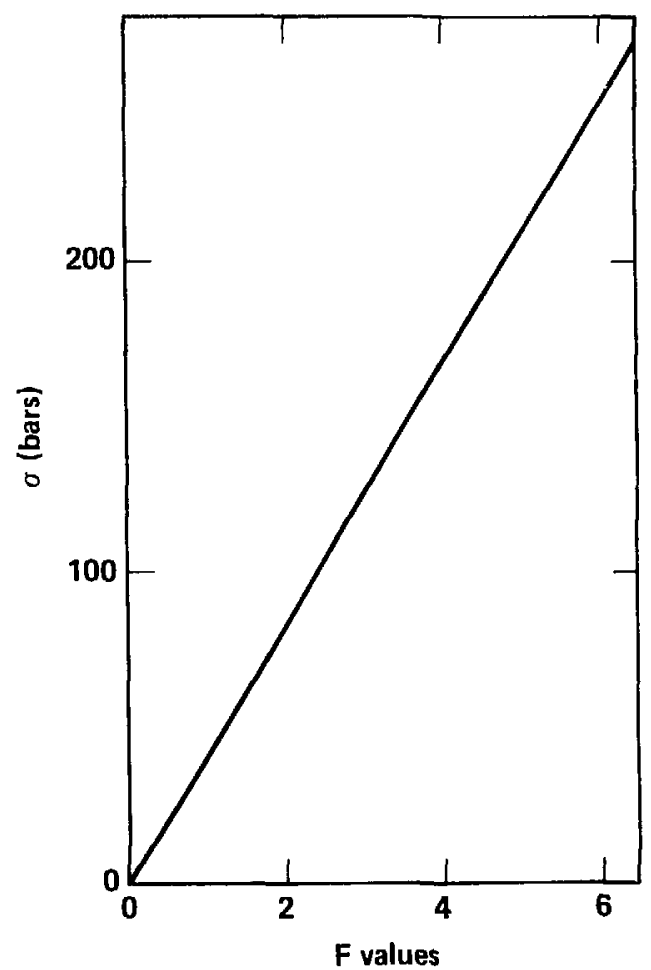


Table 2. Structure in the source region. Shear-wave velocities are computed assuming a poisson's ratio of 0.25 .

Thickness $(\mathrm{km}) \quad \mathrm{v}_{\mathrm{p}}(\mathrm{km} / \mathrm{s}) \quad$ Density $\left(\mathrm{g} / \mathrm{cm}^{3}\right)$

\begin{tabular}{ccc}
\hline 1 & 4.80 & 2.7 \\
31.5 & 6.15 & 2.8 \\
$\infty$ & 8.20 & 3.3 \\
\hline
\end{tabular}

Table 3. Structure in the receiver region. Shear-wave velocities are computed assuming a Poisson's ratio of 0.25 .

\begin{tabular}{cccc}
\hline Thickness (km) & $v_{p}(\mathrm{~m} / \mathrm{s})$ & $v_{s}(\mathrm{k} / \mathrm{s})$ & Density $\left(\mathrm{g} / \mathrm{cm}^{3}\right)$ \\
\hline 10 & 5.64 & 3.25 & 2.67 \\
32.5 & 6.04 & 3.69 & 2.71 \\
$\infty$ & 8.15 & 4.71 & 3.32 \\
\hline
\end{tabular}

Table 4. Structure for the surface waves. Shear-wave velocities are computed assuming a poisson's ratio of 0.25 .

$\begin{array}{ccccc}\text { Thickness }(\mathrm{km}) & \mathrm{V}_{\mathrm{p}}(\mathrm{km} / \mathrm{s}) & \text { Density }\left(\mathrm{g} / \mathrm{cin}^{3}\right) & Q_{\alpha} & Q_{B} \\ 1 & 4.80 & 2.7 & 600 & 250 \\ 31.5 & 6.15 & 2.8 & 600 & 250 \\ \infty & 8.20 & 3.3 & \infty & \infty\end{array}$


A primary tool for discrimination between explosions and earthquakes is the relationship between $M_{s}$ and $m_{b}$. Our results are consistent with those of Bache (1976) for $\mathrm{m}_{b}$ because we, too, believe tectonic release has very little effect. We differ somewhat from Patton $(1980)$ in regard to $M_{S^{*}}$ This is most likely due to differences in measurement methods and propagation effects. A discussion of these differences follows.

Body wave magnitudes, $m_{b}$, are computed by measuring the maximum amplitude and period of the synthetic P-wave displacementgram after it has been convolved with the response of a WWSSN-SP seismometer. The magnitude relation used is

$m_{b}=\log \frac{A}{T}+b(\Delta)$,

where $A$ is half the maximum peak-to-peak amplitude in nanometres, $T$ is the period in seconds, and $b(\Delta)$ is the distance-depth function (Gutenberg and Richter, 1956). The actual values of the distance-depth function are not important since all magnitude values are reported as differences from the isotropic source.

The period of the P-wave due to the isotropic part is shorter than that for the deviatoric part $(F=\infty)$. However, the period of the composite wave is consistent at around $0.37 \mathrm{~s}$ [the period due to the isotropic source (Fig. 5) ]. Tr? deviatoric part of the source does not affect the dominant periods of the p-wave.

Figure 5. Period of the P-wave for different $F$ values relative to the isotropic source $[\square=$ the explosion (isotropic) source, $\Delta=$ the isotropic and thrust source, $O=$ the isotropic and strike-slip source].

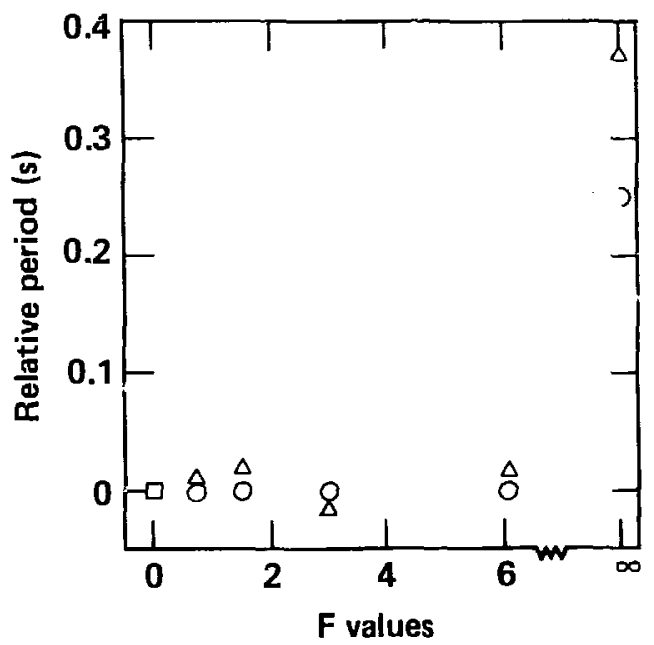


Surface wave magnitudes are computed by measuring the amplitude and period of the Rayleigh waves after the displacementgram is convolved with the response of a WWSSN-LP seismometer. Magnitudes are computed from the relation

$M_{S}=\log \frac{A}{T}+1.66 \log \Delta+0.3$

(Băth, 1973), where $\mathrm{A}$ is half the maximum peak-to-peak amplitucie in nanometres, $T$ is the period in seconds, and $\Delta$ is the epicentral distance in degrees.

As can be seen in Fig. 6, the Rayleigh-wave periods for the deviatoric parts alone $(F=\infty)$ are slightly longer than those from the isotropic part. Unlike the P-waves, however, the Rayleigh wave periods for the combined isotropic and deviatoric parts show some variation as the $F$ value is changed. Although the variation is small, Fig. 6 shows that the Rayleigh wave periods are more sensitive to tectonic strain release than are the $P$ waves. The Rayleigh wave periods for the purely isotropic part are approximately 18.2 s. Magnitudes are calculated at each station and then averaged over each of the two distributions of seismic stations. The magnitudes are plotted in Figs. 7-10 with respect to the isotropic source. For the combined source involvi.ag the thrust event ( $F^{:}, \quad 7$ and 8 ), we find that $m_{b}$ is diminished

Figure 6. Period or the Rayleigh wave for different $F$ values relative to the isotropic source $\square=$ the explosion (isotropic) source, $\Delta=$ the isotropic and thrust source, $O=$ the isotropic and strike-slip zource].

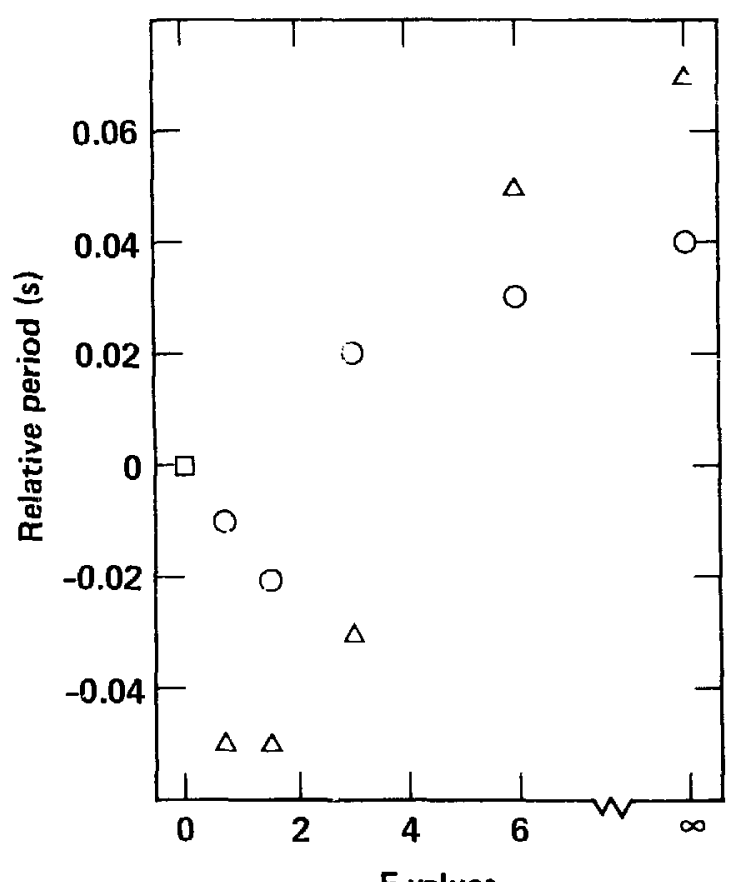

F values 


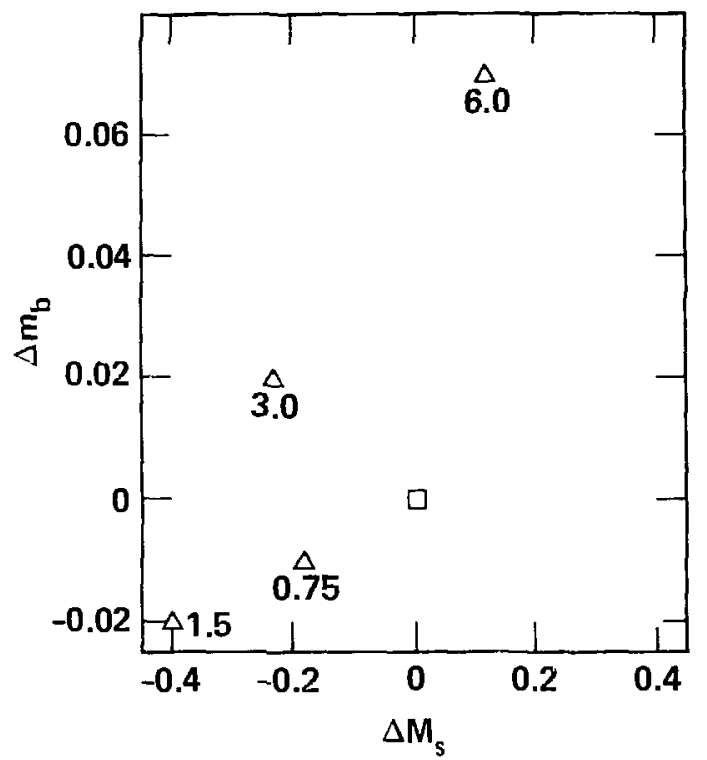

Figure 7. Effect of a thrust-slip deviatoric component on the magnitudes in an axially symmetric distribution of stations. $F$ values are next to symbols $[\square=$ the explcsion (isotropic) source and $\Delta$ $=$ the isotropic and thrust source].

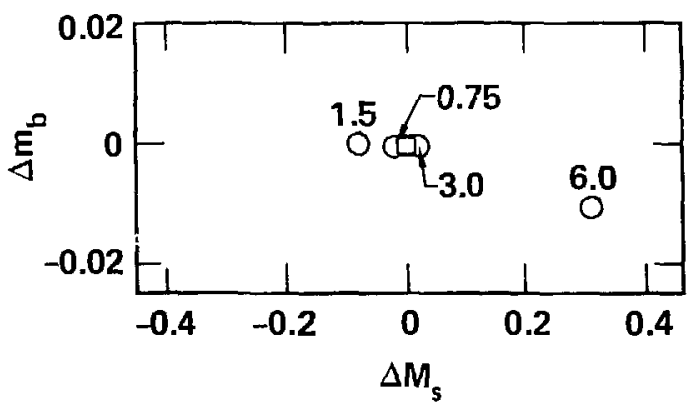

Figure 9. Effect of a strike-slip deviatoric component on magnitudes in an axially symmetric distribution of stations. $F$ values are next to symbols $[\square=$ the explosion (isotropic) source and $O=$ the isotiopic and strike-slip source].

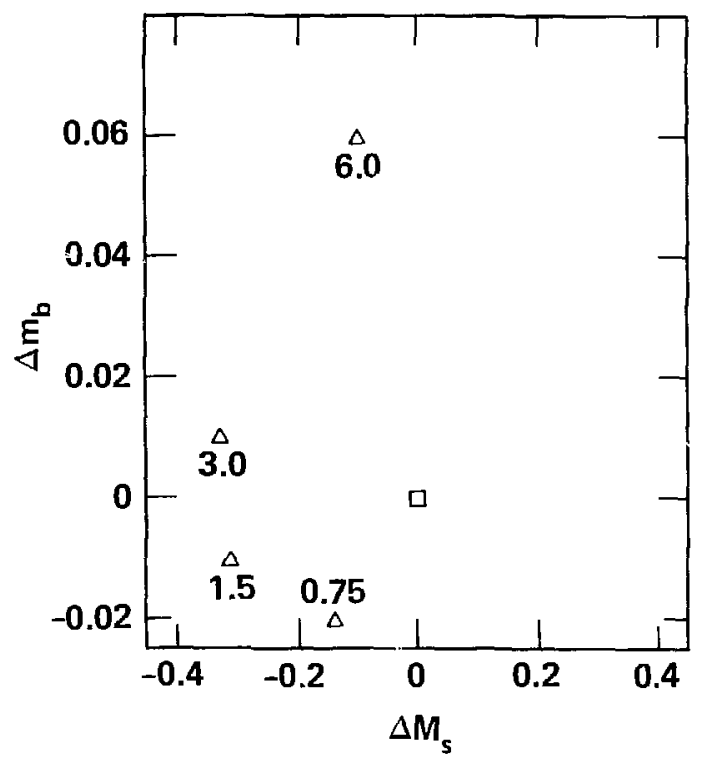

Figure 8. Effect of a thrust-slip deviatoric component on the magnitudes in a realistic distribution of stations. F values are next to symbols [ $\square=$ the explosion (isotropic) source and $\Delta=$ the isotropic and thrust source].

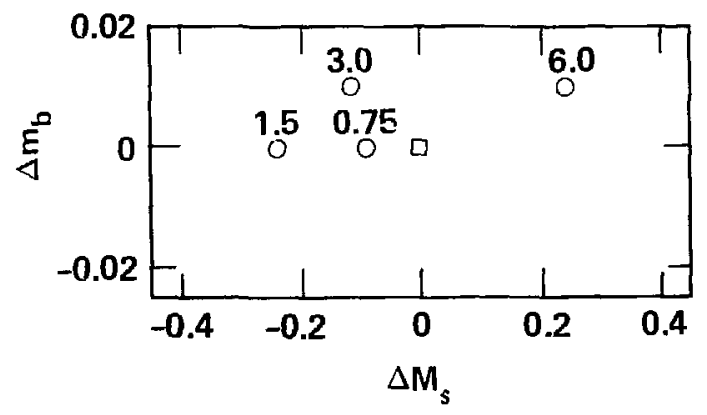

Figure 10. Effect of a strike-slip deviatoric component on magnitudes at a realistic distribution of stations. $F$ values are next to symbols $[\square=$ the explosion (isotropic) source and $O=$ the isotropic and strike-slip source]. 
for $F$ values of 0.75 and 1.5. A magnitude change of 0.02 units corresponds to a yield difference of about $8 \mathrm{kt}$ for yields near $150 \mathrm{kt}$. The accuracy of the teleseismic magnitude measurements is generally less than 0.02 units. An $F$ value of 6 increases $m_{b}$ by 0.06 to 0.07 units, with a corresponding increase in yield of about $30 \mathrm{kt}$ for yields of $150 \mathrm{kt}$.

Surface wave magnitudes display much greater sensitivity to both $F$ values and station distribution than does $m_{b}$. The effect of station distribution can be determined from examination of the deviatoric source alone (no isotropic component). The $M_{S}$ for the realistic distribution is 0.14 units below that for the equiazimuthal distribution. The $F$ value goes as the proportion of deviatoric to isotropic components. Therefore, larger values of $F$ produce $M_{S}$ more dependent on the azimuthal sampling than the $M_{S}$ produced by smaller vaiues of $\mathrm{F}$.

variations in $M_{S}$ have great implications for yield of the device. Assuming a slope of 1 in the magnitude-log yield relation, a magnitude variation of 0.3 corresponds to a factor of 2 in the yield. Yield determination from surface waves is inaccurate for high F-value explosions because the radiation pattern of the deviatoric component dominates. Body wave magnitudes are less polluted by the deviatoric component and, hence, permit a more accurate estimate of yield. Since surface wave magnitudes are more sensitive to the deviatoric component, they would be an accurate incication of the tectonic contribution.

The results for the deviatoric part consisting of a strike-slip source is displayed in Figs. 9 and 10 for the two distributions of stations. Contributions to $\mathrm{m}_{b}$ fron the deviatoric part are negligible. However, $\mathrm{M}_{S}$ is affected to the same degree as when the deviatoric source is a thrust with variations in magnitude up to 0.5 units. Comparison of Figs. 9 and 10 shows that magnitude also depends on receiver distribution. Surface wave magnitudes from both station configurations for the strike-slip source differ by 0.1 magnitude units.

The effect of propagation may be investigated by comparing the magnitude determined in this study with those determined by Patton (1980). The magnitudes from both studies are plotted in Fig. 1l. Patton's values are from Fig. 10 of his report (1980). The values from this study are for the axially symmetric case and include only points within a factor of 4 from the peak value. This procedure is similar to that used by patton. The greatest difference occurs at an $F$ of 0.75 for the case where the deviatoric part is a 


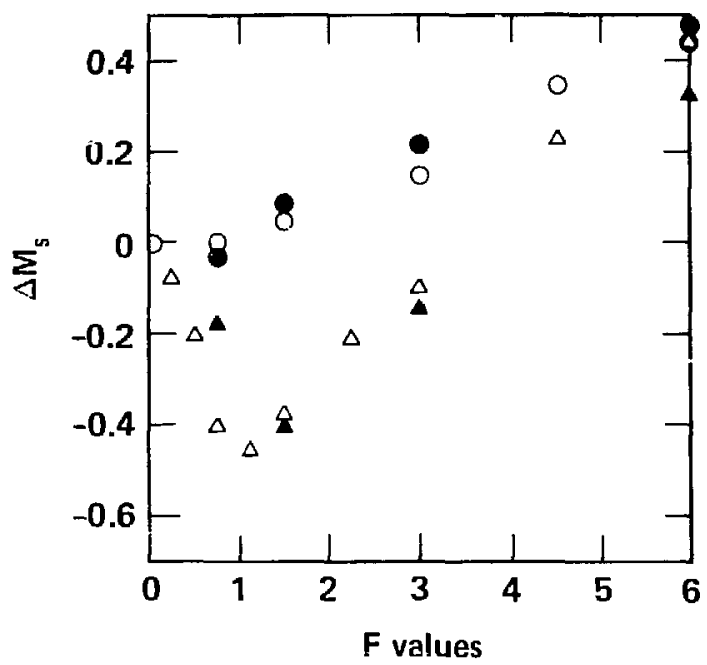

Figure 1l. Change in $\mathrm{M}_{\mathrm{S}}$ as a function of $F$. Open symbols are Patton's (1980) values, darkened symbols are ours $(\mathrm{O}=$ strike-slip and $\Delta=$ thrust slip).

thrust-slip source. In this case, the cancellation between the isotropic and deviatoric components is not as efficient for the propagated waves as for the vaves measured in the frequency domain at the source.

In summary, surface waves are much more sensitive to the deviatoric part of the source than are body waves. For certain $F$ values, the effect on ${ }^{M}$ when measured in the time domain is different from that predicted by measurements in the frequency domain. To match the Shagan River explosions (where phase reversals are observed at most azimuths for some events), a deviatoric component is needed with $F$ of at least 1.5 . With this value of $F$, the inferred yield of surface waves may vary considerably from the actual yield.

THE EFFECT OF TECTONIC STRAIN RELEASE ON RAYLEIGH WAVE DELAYS

Rygg (1979) first reporte: that a few underground explosions in the eastern Kazakhstan tast area of the Soviet Union showed Rayleigh waves that were delayed as well as phase-reversed when compared to "normal" explosiuns. Rygg found delays of as much as $4 \mathrm{~s}$. Cleary (1981) confirmed these results, using relccated epicenters. Rygg found the anomalous delays at two SRO stations, one of which was to the northwest and the other to the southeast. Cleary found anomalous Rayleigh waves for stations to the northeast and southwest. The reason for this discrepancy is not clear; however, it could be due to location errors by Rygg (North and Fitch, 1982). Both authors found 
that Love waves from the anomalous events were not delayed with respect to the "normal" explosion.

Rygg suggested that spall and slapdown are the only mechanisms that could account for the delay. Cleary proposed an explosion source time function that is modified by the tectonic release such that the long period is actually reversed from that of the explosion itself. Cleary's model does not address the observation that Love waves appear to be neither reversed nor delayed.

The 20-s Rayleigh wave reflects both the initial phase of the wave and the effects due to propagation. We checked the phase of the Rayleigh waves from isotropic sources with a tectonic (deviatoric) component against the phase from the isotropic source alone. In an additional experiment, the origin time of the deviatoric component follows the isotropic compurent, approximating the conditions of a triggered earthquake. It is unclear whether the origin times of the isotropic and deviatoric parts really differ. Love waves from events showing delayed Rayleigh waves are not observed to be delayed when compared to Love waves from events with normal Rayleigh waves. Therefore, we compared the waveforms of Rayleigh waves of different $F$ values with the waveforms from the isotropic explosion to determine the effect of the deviatoric part for these two cases.

Measurements are made relative to the phase arrival time of the characteristic " $w$ " in the 18- to 22-s Rayleigh wave from the isotropic source. This phase arrival time is the reference to which all subsequent measurements are compared. The Rayleigh waveforms are visually checked to see whether the composite-source Rayleigh wave is normal or reversed when compared to the purely isotropic source. The term "reversed" means that the Rayleigh wave signal is multiplied by -1 . A positive phase delay means that the investigated signal arrives after the corresponding phase for the isotropic source.

The behavior of Rayleigh waves in isotropic and deviatoric sources of the same origin time can be seen if Figs. 12-15 are compared. The phase of the observed Rayleigh wave is a function of the source initial phase as well as the path dispersion effects. When a composite source has a thrust-slip source as its deviatoric part, the composite source arrives prior to the wave from the purely isotropic source. The phase difference is less than $2 \mathrm{~s}$. However, for $F$ values and azimuths where reversals are present, the Rayleigh waves are delayed for up to $4 \mathrm{~s}$ (Figs. 12-15). The delays are particularly large at $\mathrm{F}$ 


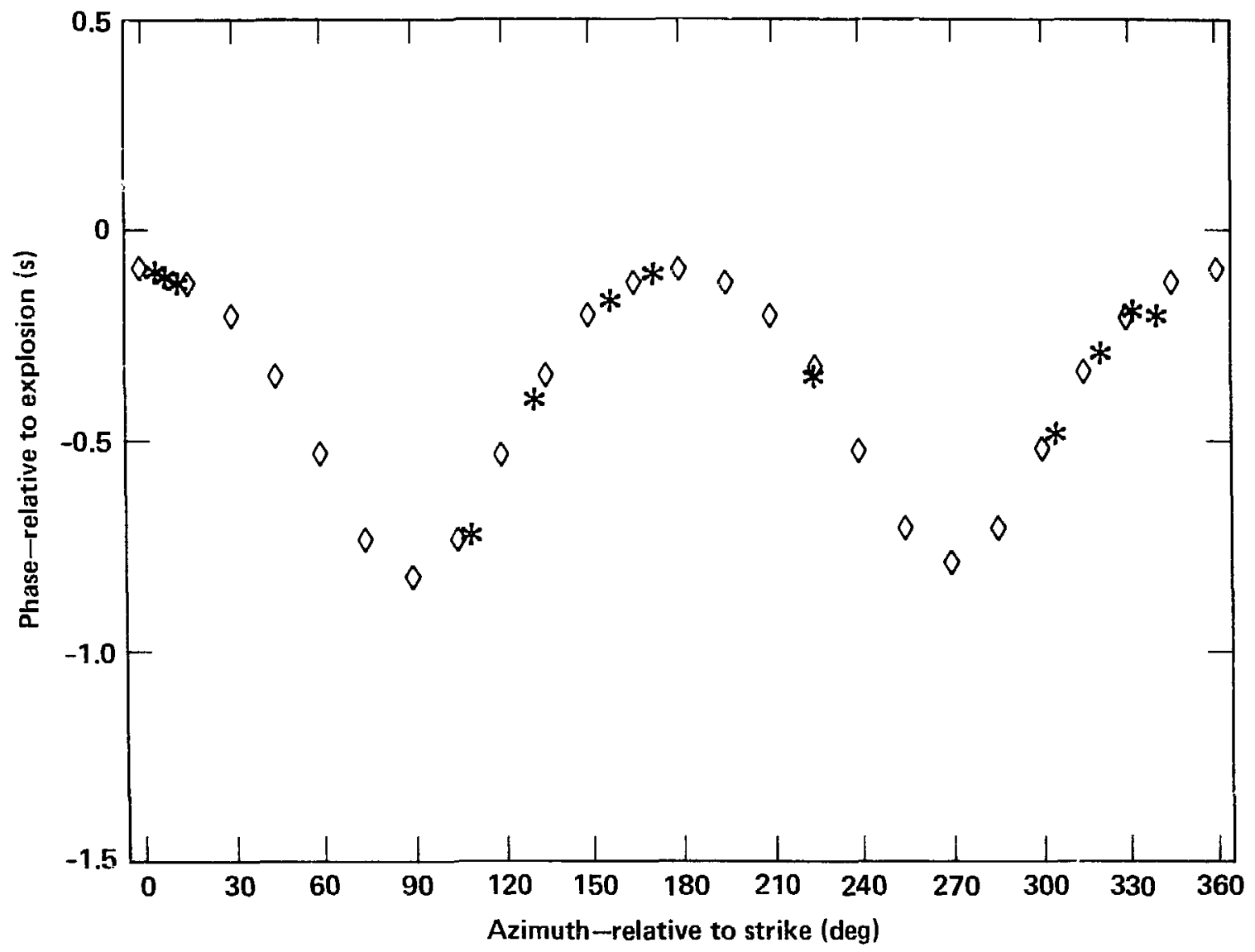

Figure 12. Comparison of Rayleigh waves from a source with a thrust-slip deviatoric part and an isotropic explosion as a function of azimuth. $F=0.75$ ( $O=$ normal waves for an equal distribution of stations, and * = reversed waves recorded on a realistic distribution of stations).

values of 1.5 and 3.0. The observations by cleary can be explained by an explosion within an $F$ value of 1.5 to 3.0 and a fault striking at about $135^{\circ}$. As stated above, the observations of Rygg are not considered to be as accurate due to possible location errors, which resulted in phase shifts. His observations will not therefore, be considered in this discussion. The phase delays for the reversed waves decrease for $F$ values of 6 . This is primarily due to the dominance of the deviatoric part; the result is a small, constant phase difference between the isotropic source with tectonic release and the purely isotropic source. 


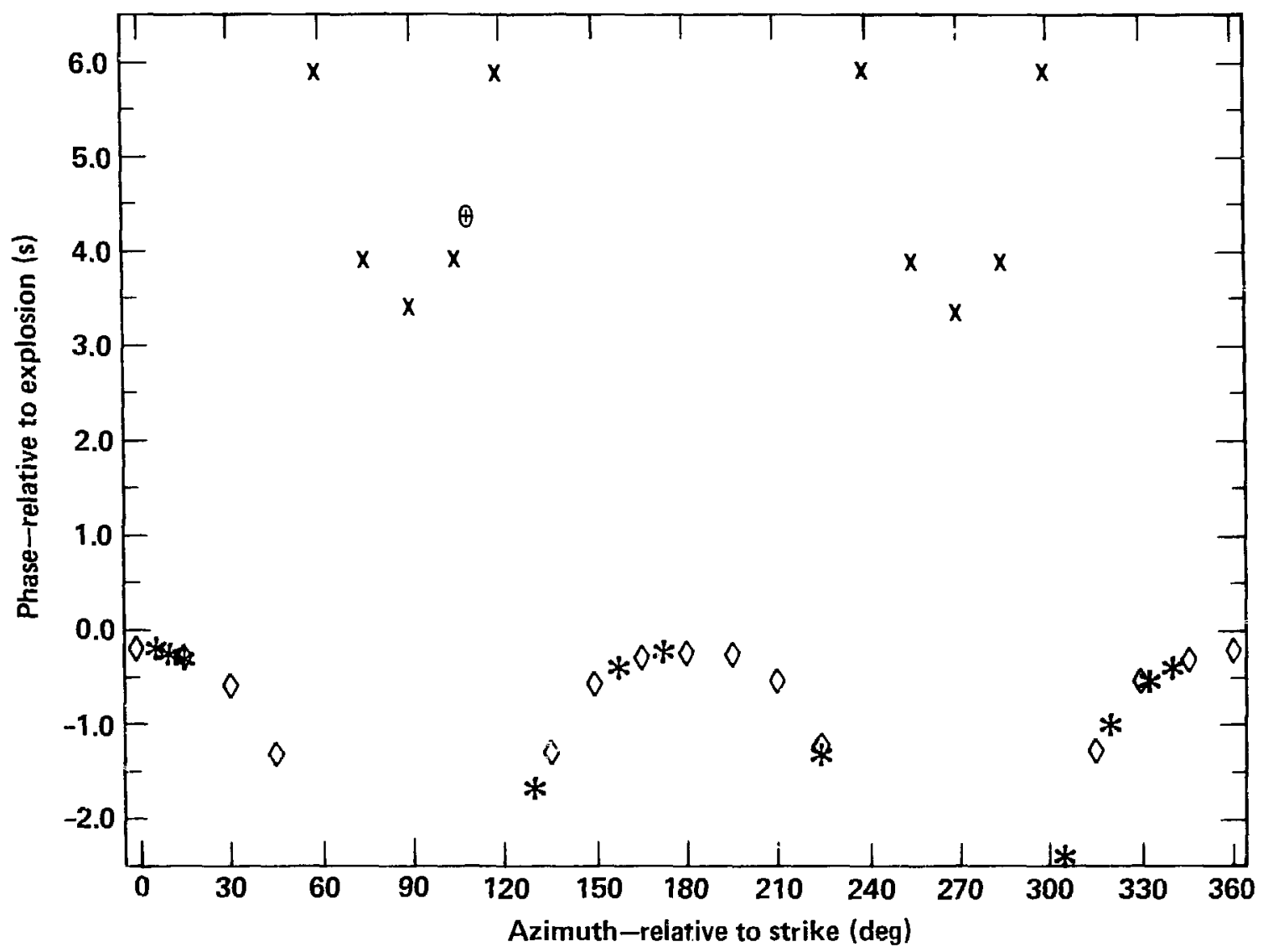

Figure 13. Comparison of Rayleigh waves from a source with a thrust-slip deviatoric part and an isotropic explosion as a function of azimuth. $F=1.5(X=$ reversed waves for an equal distribution of stations, * = normal waves recorded on a realistic distribution of stations, $\oplus=$ reversed waves recorded on a realistic distribution of stations, and $O=$ normal waves for an equal distribution of stations).

The thrust-slip model of tectonic strain release is the preferred mechanism for the Shagan River region. This mechanism explains the reversals we observed in some quadrants and the delays in the reversed Rayleigh waves. The strike-slip model cannot account for reversals in all azimuths (Patton, 1980). It does show reversals in some azimuths (Fig. 16). However, the azimuths showing a delay of $4 \mathrm{~s}$ are so narrow that this is an unlikely model of tectonic release.

Suppose that the deviatoric part of the source follows the isotropic part. With the thrust-slip case for the deviatoric part, we put in a 


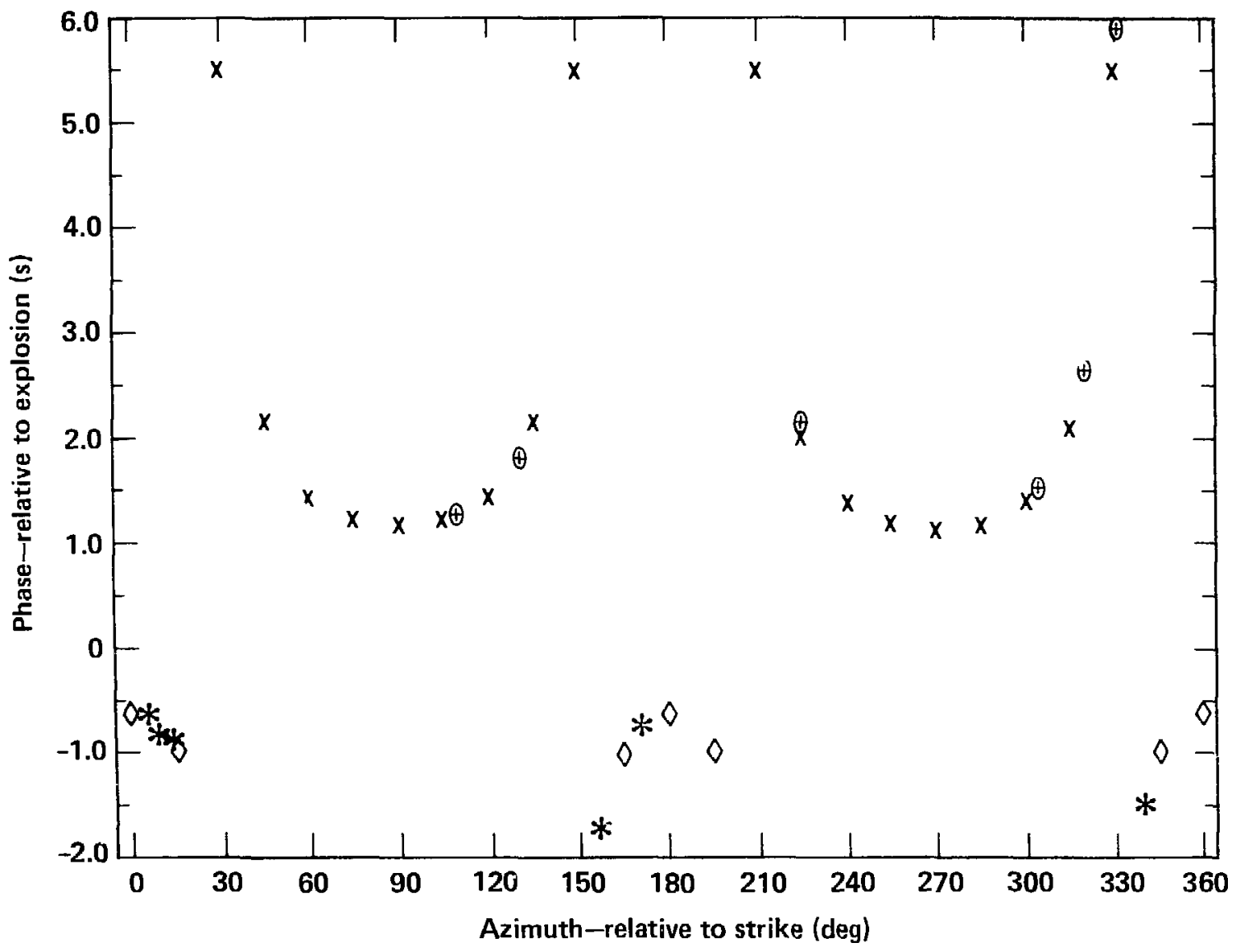

Figure 14. Comparison of Rayleigh waves from a source with a thrust-slip ceviatoric part and an isotropic explosion as a function of azimuth. $F=3.0(X=$ reversed waves for an equal distribution of stations, * = normal waves recorded on a realistic distribution of stations, $\boxplus=$ reversed waves recorded on a realistic distribution of stations, and $\diamond=$ normal waves for an equal aistribution of stations).

difference in origin time (delay) of $1 \mathrm{~s}$. The results are illustrated in Figs. 17-20. A comparison of results from coincident origin times shows that the difference in origin time has little effect on delays for azimuths that show normal Rayleigh waves. However, for the reversed Rayleigh waves, the time difference adds linearly to the observed phase delays. This property is tested for differences (delays) of 2 and $4 \mathrm{~s}$ and is found to be consistent. As can be seen from Fig. 19, reversals at nearly all azimuths, and phase delays of 3 to $4 \mathrm{~s}$ can be easily explained by an $F$ of 1.5 to 3 and a difference in source origin time of about $1 \mathrm{~s}$. 


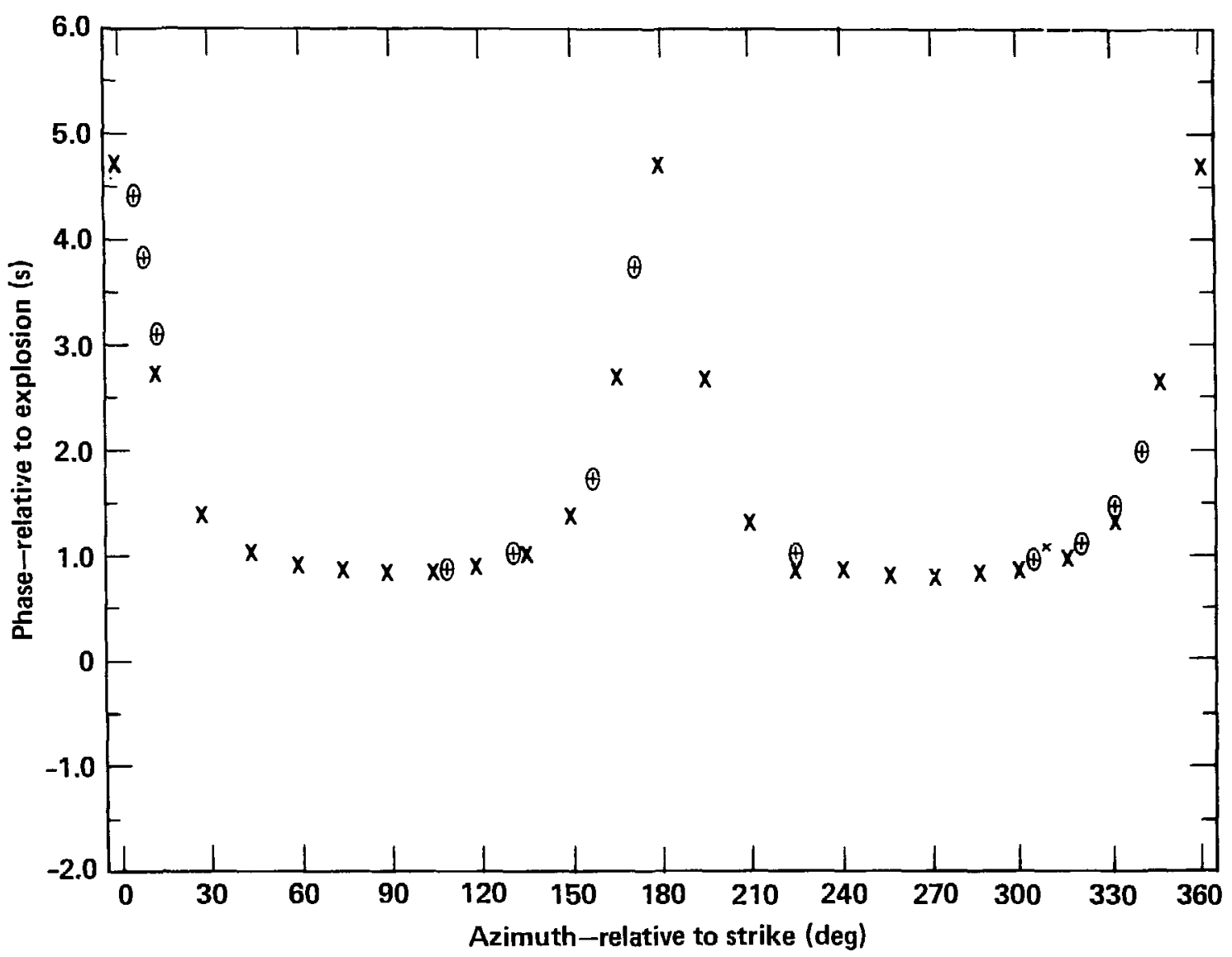

Figure 15. Comparison of Rayleigh waves from a source with a thrust-slip deviatoric part and an isotropic explosion as a function of azimuth. $F=6.0(X=$ reversed waves for an equal distribution of stations, $\oplus=$ reversed waves recorded on a realistic distribution of stations).

From the previous discussion, we can see that interference between the Rayleigh waves from the isntropic and deviatoric parts results in waves that are both reversed and delayed when compared to the purely isotropic source. The reversals have already been explained by Harkrider (1981) and Patton (1980) as being due to the source phase. The effect they describe shows either a normal or reversed $\left(180^{\circ}\right.$ shift) phase. The time delay observed in this study is the result of combining the many frequencies in the band of the 20-s Airy phase. All of the frequencies add up to the $\sim 20 \mathrm{~s}$ arrival used in the computation of $\mathrm{M}^{\mathrm{s}}$. 


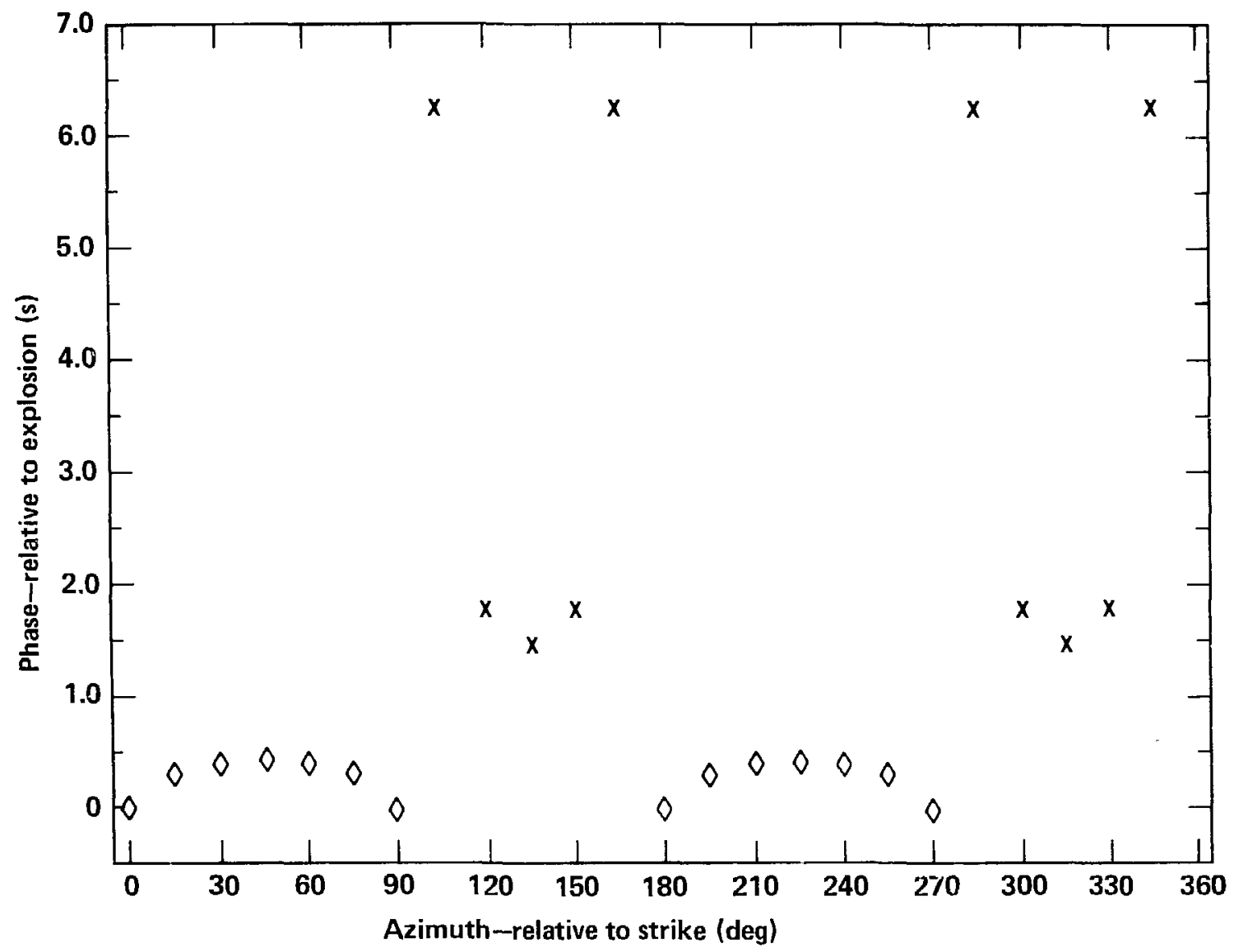

Figure 16. Comparison of Rayleigh waves from a source with a strike-slip deviatoric part and an isotropic explosion as a function of azimuth. $F=3.0(X=$ reversed waves for an equal distribution of stations and $O=$ normal waves for an equal distribution of stations).

From Figs. 12-15, we see that propagation path length has very little effect on the delay. Despite the fact that the source-to-receiver distances differ for two cases, the delays for the axially symmetric case are consistent with those for the realistic distribution. The delay is due to a difference in source phase.

Our source model differs from those used by Patton (1980). Patton used a step source time function in the isotropic source, as opposed to the Haskell (1967) model of this study. Patton found only normal or reversed waves with no phase delays. Figure 2 shows the difference in the initial phase of the two source models. At $20 \mathrm{~s}$, the step function has a source phase delay of 0.375 circle, whereas Haskell's source time function has a source phase delay of 0.3666 circle. 


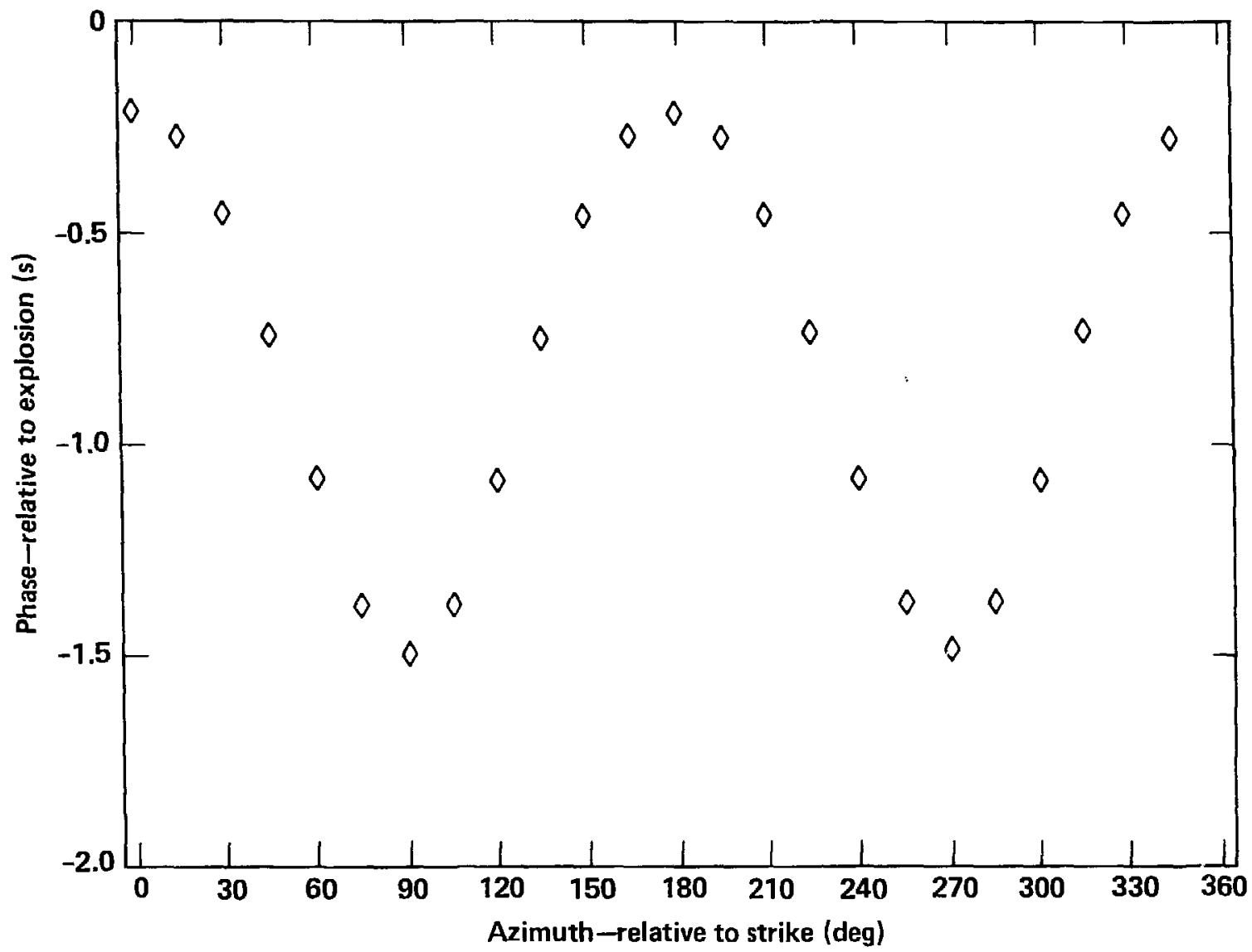

Figure 17. Comparison of Rayleigh waves from a source with a thrust-slip deviatoric part and an isotropic explosion as a function of azimuth. $F=0.75(O=$ normal waves for an equal distribution of stations). Origin of thrust-slip part is 1 s later than the isotropic part.

The phase delay for the present deviatoric source is azimuthally dependent. Suppose we choose a demonstration azimuth of $90^{\circ}$. Patton (1980) assumed a point source with a step source time function, producing a source phase of 0.875 circle. Savage's (1960) model is a finite source with a finite rupture velocity. The source phase is plotted on Fig. 3 . At $20 \mathrm{~s}$, the Savage source has a phase of 0.900 circle.

Thus, in Patton's (1980) work, the isotropic and deviatoric parts differ in phase by 0 or 0.5 circle. This study used the Haskell and Savage models, with a phase difference of 0.0333 and 0.5333 circle, respectively. We find it surprising that a phase difference of 0.0333 circle would cause a phase delay as large as $4 \mathrm{~s}$ in the composite source. To investigate this effect, we added two monochromatic waves with known amplitude and phase relations and examined 


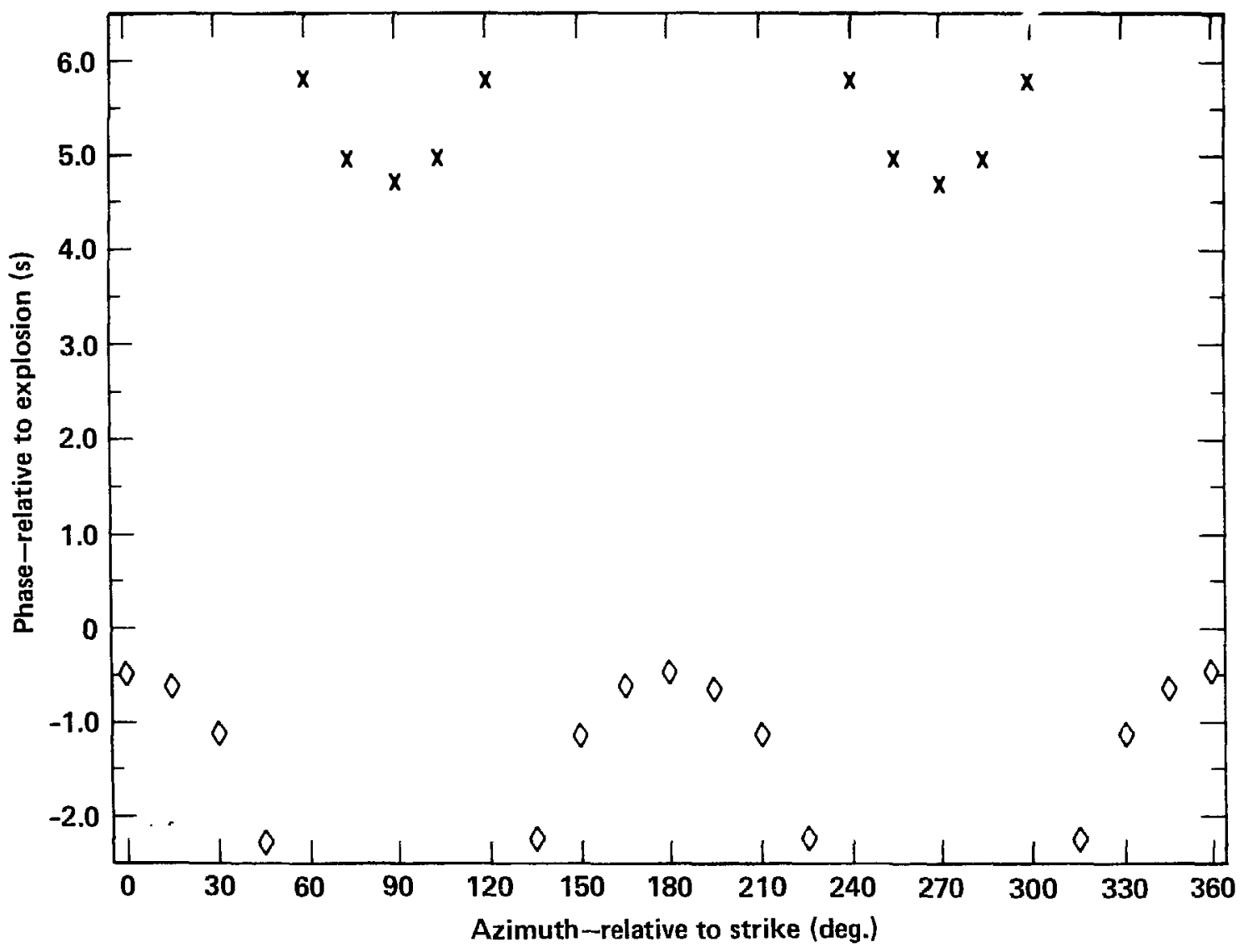

Figure 18. Comparison of Rayleigh waves from a source with a thrust-slip deviatoric part and an isotropic explosion as a function of azimuth. $F=1.5(X=$ reversed waves for an equal aistribution of stations and $\diamond=$ normal waves for an equal distribution of stations). Origin of thrust-slip part is 1 s later than the isotropic part.

the phase of the composite signal. The results are plotted in Fig. 2l. The abscissa represents the phase difference between the reference and secondary waves. Phase differences of 0 and 1 circle correspond to waves in phase. A phase difference of 0.5 circle corresponds to the case where the waves are out of phase. The ordinate represents the phase of the composite wave relative to the reference wave. Each curve represents the amplitude of the secondary wave with respect to the reference wave. As can be seen, phase reversals of the composite wave, relative to the reference wave, occur when the secondary wave is out of phase with the reference wave and of larger amplitude. 


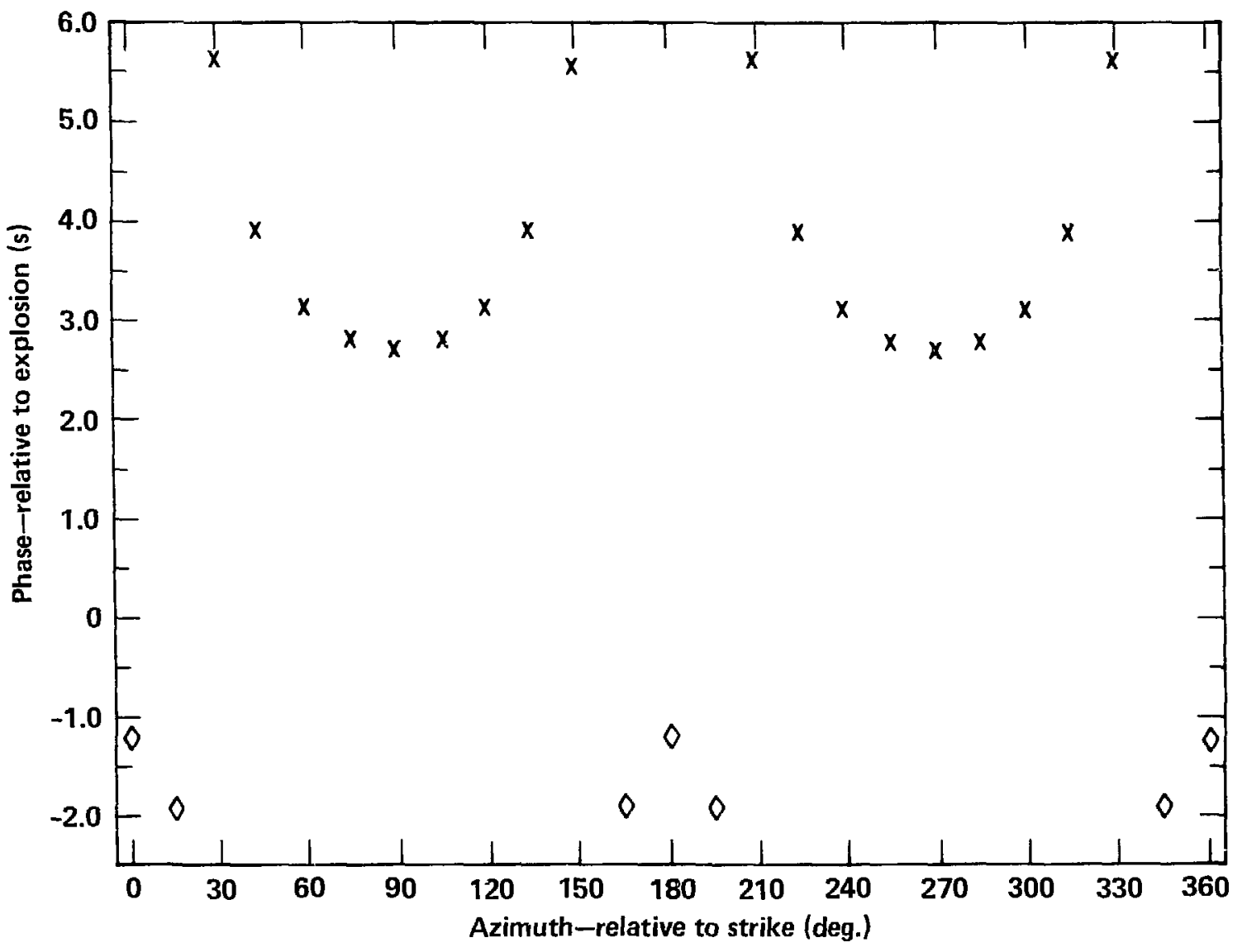

Figure 19. Comparison of Rayleigh waves from a source with a thrust-slip deviatoric part and an isotropic explosion as a function of azimuth. $F=3.0(X=$ reversed waves for an equal distribution of stations and $\vartheta=$ normal waves for an equal distribution of stations). Origin of thrust-slip part is 1 s later than the isotropic part.

It is obvious that phase delays are possible if the phase difference between the reference and secondary events is different from 0.5 circles, as in the case of the Haskell and Savage sources. As the amplitude ratio increases beyond 1 , the wave phase is reversed. Phase differences between the reference and secondary events (other than 0.5 circle) cause phase shifts with the maximum shift at amplitude ratios near 1. Reversed and delayed Rayleigh waves imply that the wave from the deviatoric (secondary) source is slightly larger than (and its phase slightly ahead of) the wave from the isotropic (reference) source. In this study, a unit amplitude ratio corresponds to an $F$ value of 1.3 . 


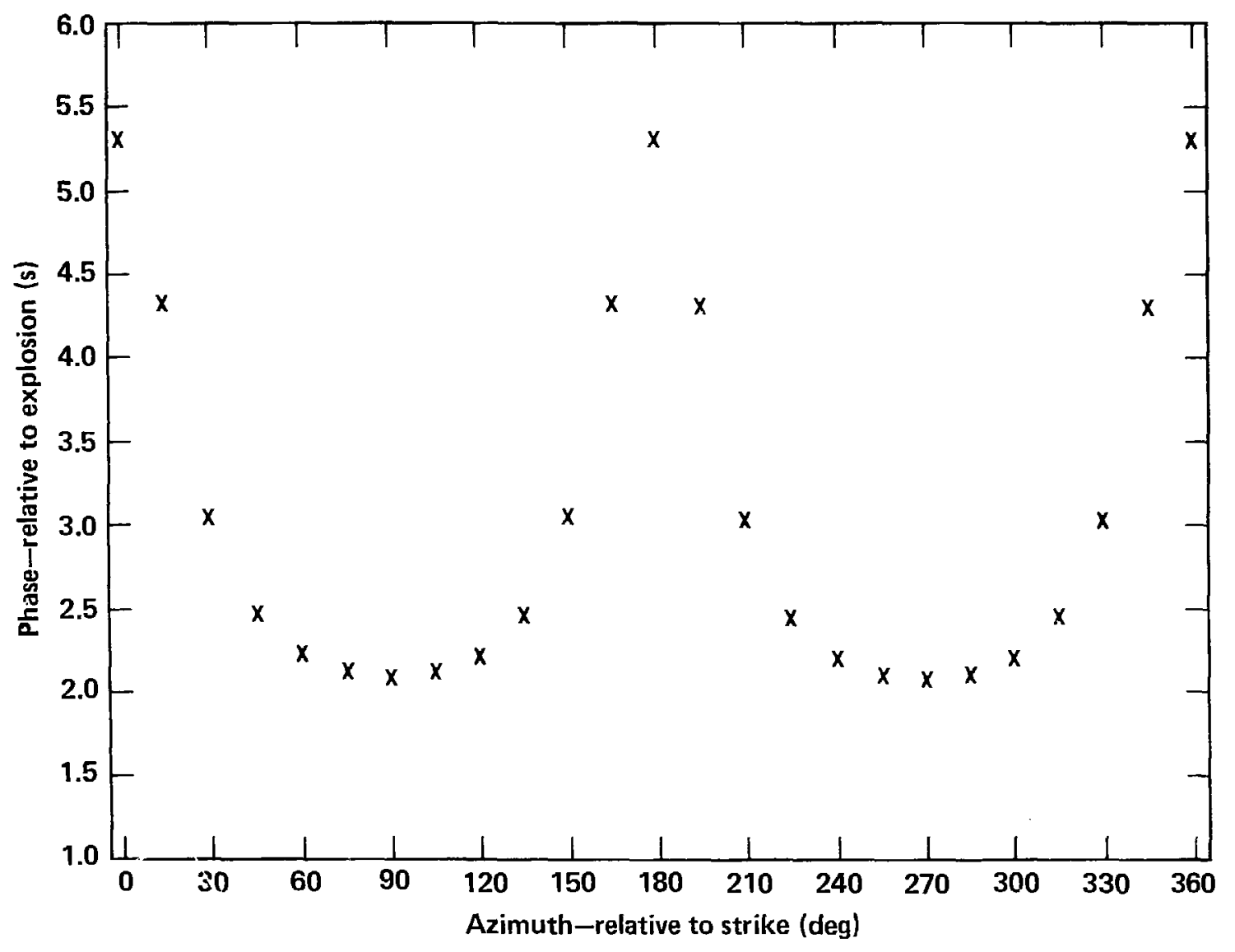

Figure 20. Comparison of Rayleigh waves from a source with a thrust-slip deviatoric par'c and an isotropic explosion as a function of azimuth. $F=6.0$ ( $X=$ reversed waves for an equal distribution of stations). Origin of thrust-slip part is 1 s later than the isotropic part.

IMPLICATIONS FOR TECTONICS OF THE SOURCE REGION

To match the observations of cleary, the fault in the thrust-slip model must be aligned in the northwest-southeast direction. This orientation is less restrictive for the larger $F$ values since there are more azimuths over which reversals occur. Such an orientation is consistent with Landsat photographs of faults in the eastern Kazakhstan region (Fig. 42, Rodean, 1979). The strikes of these faults are approximately $155^{\circ}$ from north. The only event in this region that has been studied in detail is the presumed earthquake of March 20, 1976. Rodean (1979) reports on the work of $R$. Pearce, in which Pearce finds that the events can be modeled by strike-slip motion on a vertical fault plane in the north northeast-south southwest direction. 


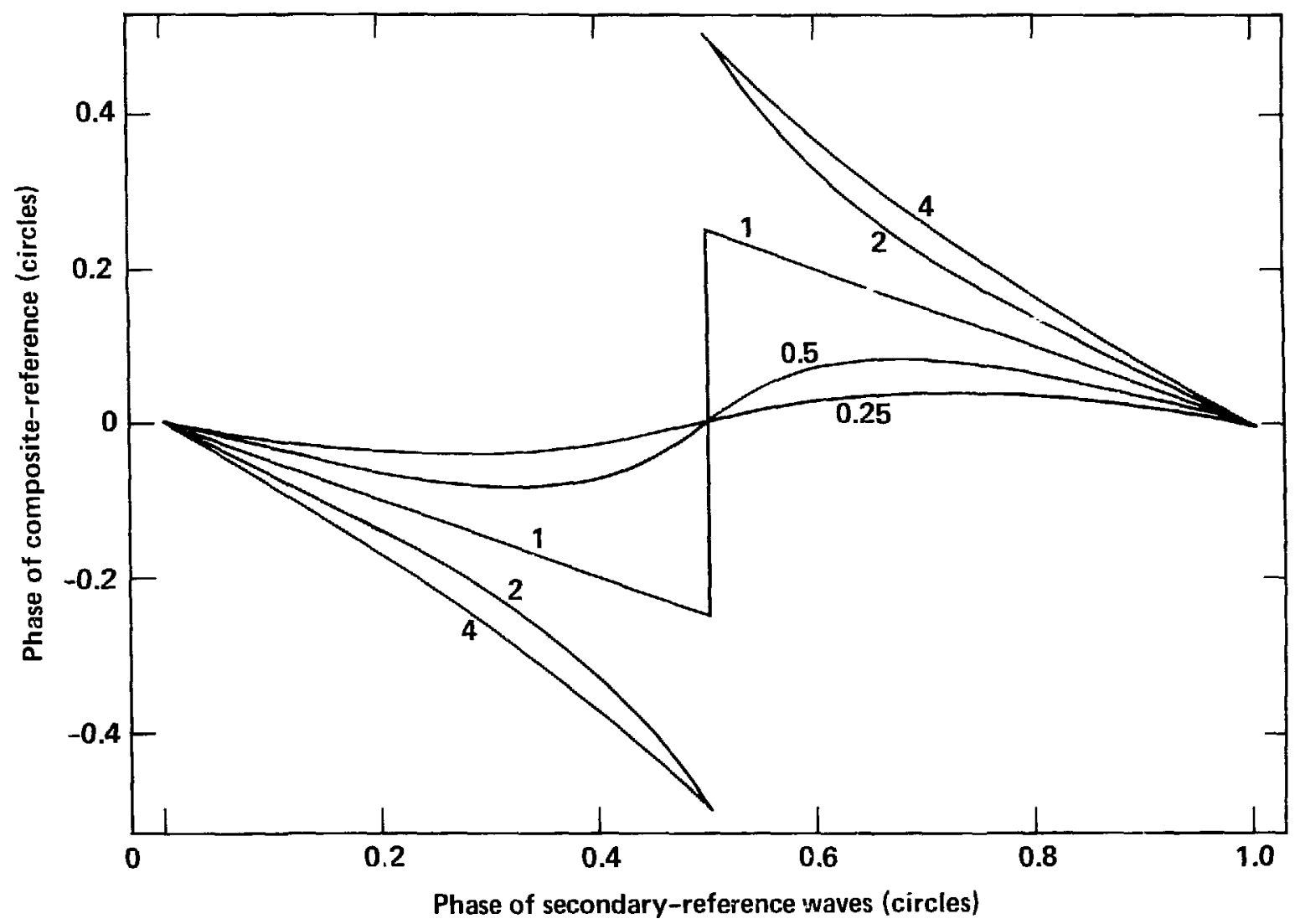

Figure 21. Phase of composite signal relative to the reference vs phase difference between the reference and secondary waves. Value on each curve represents a different proportion in amplitude between the secondary to reference waves.

The maximum principal stress in this region is inferred to be north-south compression (Tapponnier and Molnar, 1979). This is consistent with thrust motion along northwest-southeast strikes. The exact mechanism could be a combination of thrust and strike-slip motion. These mechanisms would generate reversals and delays (Figs. 14 and 16 ) consistent with the observations.

SUMMARY

The release of tectonic strain accompanying underground nuclear explosions posas many problems in discrimination, identification, and yield determination. In this study, we modelled tectonic strain release by 
superimposing an earthquake on an explosion. Synthetic seismograms are used such that measurements are made in the time domain and include the effects of both source and propagation.

We find that body wave magnitudes are not influenced by tectonic re?ease. However, surface wave magnitudes show sensitivity to tectonic release and receiver locations. This dependence makes $M_{s}$ unreliable as a determinant of yield.

Both reversals in the Rayleigh wavetrain and observed phase delays may be explained without resorting to complex source time functions or spallation. Reversals in a few or even in all azimuths are explained by adding various levels of the deviatoric source to the isotropic source. We find that delays occur when the interfering waves are about equal to each other in amplitude and slightly out of phase. The source phases from realistic models (such as the Haskell and the Savage source) are sufficiently different that the composite wave shows a phase delay where compared to the normal explosion. We find that the delays of the composite source increase with an increase in the difference between the origin times of the isotropic and deviatoric parts. Thus, a delay of $4 \mathrm{~s}$ can be explained without resorting to complex source models.

The phase delays can be explained by a simple interference between the isotropic and deviatoric sources. The phase delays were not observed by Patton (1980) because the phases of source models chosen differed by ze ro or 0.5 circle. By employing models with different source phases, such as those by Haskell and Savage (used in this study), we may predict reversals and phase delays.

To match observations, the direction of faulting for the tectonic release sources is inferred to be northwest-southeast. A thrust mechanism is preferred in order to have reversals for certain events at some azimuths and reversals at all azimuths for others. Thrust motion does not match the inferred motion along a known fault near the Shagan River region. However, thrust slip is consistent with the known regional tectonics. 


\section{ACKNOWLEDGMENTS}

We sincerely thank H. J. Patton for numerous suggestions and discussions throughout the course of this study. We also thank J. L. Stevens, who suggested that the cause of the Rayleigh wave delay is due to the source time functions. A. Douglas supplied the computer program used to compute the synthetic seismograms, for which we are deeply appreciative. Comments by J. Hannon, P. Kasameyer, P. Moulthrop, H. Patton, P. Rodgers, and S: Taylor substantially improved the manuscript. 


\section{REFERENCES}

Aki, K. (1964), "A Note on Surface Waves Generated from the Hardhat Nuclear Explosion," J. Geophys. Res. 69, 1131-1134.

Aki, K. and Y. B. Tsai (1972), "Mechanism of Love Wave Excitation of Explosive Sources," J. Geophys. Res. 77, 1452-1475.

Archambeau, C. B. (1964), "The Theory of Stress Wave Radiation from Explosions in Prestressed Media," Geophys. J. R. Astr. Soc. 29, 329-366.

Bache, T. C. (1976), "The Effect of Tectonic Stress Release on Explosion P-Wave Signatures," Bull. Seis. Soc. Am. 65, 1441-1457.

B⿳亠口冋.th, M. (1973), Introduction to Seismology (John Wiley and Sons, New York).

Brune, J. N. (1970), "Tectonic Stress and the Spectra of Seismic Shear Waves from Earthquakes," J. Geophys. Res. 75, 4997-5009.

Brune, J. N. and P. W. Pomeroy (1963), "Surface wave Radiation Patterns for Underground Nuclear Explosions and Small Magnitude Earthquakes," J. Geophys. Res. 68, 5005-5028.

Cleary, J. R. (1981), "Anomalous Rayleigh Waves from Presumed Explosions in East Kazakh," in E. S. Husebye and S, Mykkeltveit (eds.), Identification of Seismic Sources--Earthquake or Underground Explosion (D. Reidel, Dordrecht), 191-199.

Douglas, A. (1980), Ministry of Defence (Procurement Executive), Blacknest, UK (private communication).

Douglas, A., J. Hudson, and C. Blamey (1972), "A Quantitative Evaluation of Seismic Signals at Teleseismic Distances--II. Computed $P$ and Rayleigh Wave Seismograms," Geophys. J. R. Astr. Soc. 28, 385-410. 
Douglas, A., J. A. Hudson, P. D. Marshall, and J. B. Young (1974),

"Earthquakes that Look Like Explosions," Geophys. J. R. Astr., Soc. 36, 227-233.

Evernden, J. F., W. J. Best, P. W. Pomeroy, T. V. McEvilly, J. M. Savino, and L. R. Sykes (1971), "Discrimination Between Small-Magnitude Earthquakes and Explosions," J. Geophys. Res. 76, 8042-8055.

Gutenberg, B. and C. F. Richter (1956), "Magnitude and Energy of Earthquakes," Ann. Geofisica $9,1-15$.

Harkrider, D. G. (1981), "Coupling Near Source Phenomena into Surface Wave Generation," in E. S. Husebye and S. Mykkeltveit (eds.), Identification of Seismic Sources--Earthquake or Underground Explosion (D. Reidel, Dordrecht), 277-326.

Haskell, N. A. (1967), "Analytic Approximation for the Elastic Radiation from a Contained Underground Explosion," J. Geophys Res. 72, 2583-2687.

Mueller, R. A. and J. R. Murphy (1971), "Seismic Characteristics of Underground Nuclear Detonations, Part I. Seismic Spectrum Scaling," Bull. Seism. Soc. Am. 61, 1675-1692.

Müller, G. (1973), "Seismic Moment and Long-Period Radiation of Underground Nuclear Explosions," Bull. Seism. Soc. Am. 63, 847-857.

North, R. G. and T. J. Fitch (1982), "Surface Wave Generation by Underground Nuclear Explosions," J. Geophys. Res., in press.

Patton, H. J. (1980), "Surface-Wave Generation by Underground Nuclear Explosions Releasing Tectonic Strain," Lawrence Livermore National Laboratory, Livermore, CA, UCRL-53062.

Patton, H. J. (1982), Lawrence Livermore National Laboratory, Livermore, CA (private communication). 
Patton, H. J. and E. S. Vergino (1981), "Source Effects on Surface Waves from Nevada Test Site Explosions," Lawrence Livermore National Laboratory, Livermore, CA, UCRL-53247.

Rodean, H. C. (1979), "ISC Events from 1964 to 1976 at and Near the Nuclear Testing Ground in Eastern Kazakhstan," Lāwrence Livermore National Laboratory, Livermore, CA, UCRL-52856.

Rygg, E. (1979), "Anomalous Surface Waves from Undergound Explosions," Bull. Seism. Soc. Am. 69, 1995-2002.

Savage, J. C. (1966), "Radiation from a Realistic Model of Faulting," Bull. Seism. Soc. Am. 56, 577-592.

Tapponnier, P. and P. Molnar (1979), "Active Faulting and Cenozoic Tectonics of the Tien Shan, Mongolia, and Baykal Regions," J. Geophys. Res. 84 , $3425-3459$.

Troksöz, M. N. and H. H. Kehrer, (1972), "Tectonic stress Release by Underground Nuclear Explosions and Its Effect on Seismic Discrimination," Geophys. J. R. Astr. Soc. 31, 141-161.

Von Seggern, D. and R. Blandford (1972), "Source Time Functions and Spectra for Undergound Nuclear Explosions," Geophys. J.R. Astr. Soc. 31, 83-97. 